\title{
Potential threat of arsenic contamination of water sources from gold mining activities in Lake Victoria areas, Tanzania
}

\author{
R.R.A.M. Mato \& G.R. Kassenga \\ Department of Environmental Science and Management, Ardhi University, Dar es Salaam, Tanzania
}

\begin{abstract}
Occurrence of arsenic in drinking water sources is among the contemporary challenging water quality problems that need immediate attention worldwide. Both natural and human induced arsenic sources are potentially contaminating the water resources and thus exposing millions of people to serious public health risks including cancer. In some areas, mining activities, especially gold mining, have been reported to induce elevated levels of arsenic in adjacent water sources. In most developing countries like Tanzania most lack scientific information on the extent of arsenic levels in water sources. A rapid assessment conducted to determine occurrence of arsenic contamination in water sources in the Lake Victoria mining areas in Tanzania has showed elevated levels of arsenic in some areas. Arsenic levels as high as $70 \mu \mathrm{g} \mathrm{L}^{-1}$ were observed and more than $40 \%$ of the water samples taken from the areas had arsenic levels equal to or exceeding the Tanzania Drinking Water Quality Standards threshold value of $10 \mu \mathrm{g} \mathrm{L}^{-1}$. Areas with high arsenic levels included Maswa, Shinyanga and Musoma districts. The arsenic mobilization into water sources is suspected to be due to oxidation of arsenopyrite after exposure of the ore to the air partly due to mining activities. This linkage makes mining activities potential threat to quality of drinking water sources in the Lake Victoria mining areas, a reason which triggers search for safe water sources. This paper discusses the potential health risks that exists in the Lake Victoria mining areas due to exposure to arsenic contamination and appropriate measures that can be undertaken to protect the health of general public.
\end{abstract}

\section{INTRODUCTION}

Arsenic is a known water contaminant, which can have devastating effects on health (WHO, 2000). Both acute and chronic health effects can be manifested depending on the arsenic dosage and time duration of exposure. Some countries like Bangladesh experiences serious arsenic contamination (Halsey, 2000). The WHO (2000) has set the Drinking Water Guideline for arsenic at $10 \mu \mathrm{g} \mathrm{L}^{-1}$. However, drinking water arsenic limits vary from country to country based on different regulatory limits set by the governments.

Arsenic naturally occurs primarily as arsenopyrite (FeAsS), which is the most abundant arsenic mineral, dominantly in mineral veins (Halsey, 2000). Its occurrence in water sources thus has a close linkage with mining or mineral extractions. According to the BGS (2001), arsenic mobilizes in the local environment as a result of arsenopyrite oxidation, induced (or exacerbated) by the mining activity. High arsenic concentrations have been reported in soils and river waters close to the gold mining activity in Ghana (BGS, 2001; Bhattacharya et al., 2012; Kassenga \& Mato, 2008; Smedley, 1996). Arsenic contamination from mining activities has also been identified in numerous areas of the USA where concentrations of up to $48,000 \mu \mathrm{g} \mathrm{L}^{-1}$ in groundwater have been reported (Welch et al., 2000). In Bangladesh concentration of arsenic in groundwater has been reported to exceed 2,000 $\mathrm{g} \mathrm{L}^{-1}$ (Halsey, 2000).

In Tanzania, arsenic contamination in water sources has scarcely been reported. Kassenga and Mato (2008) reported elevated levels of arsenic in Lake Victoria region. Earlier, the Department of Geology, University of Dar es Salaam, Tanzania (1994) reported presence of arsenic concentrations ranging between 0.5 and $379 \mu \mathrm{g} \mathrm{L}^{-1}$ in some water and sediment samples collected from the Lake Victoria mining areas. The suspected source of arsenic pollution in the water and sediment samples was identified to be oxidation of arsenopyrite in mine tailings dumped into the rivers during gold panning.

Despite intensive mining activities in the Lake Victoria areas, there is no comprehensive study to determine the ingress of arsenic in water sources. The Lake Victoria Basin is the leading gold producing area in Tanzania. There are a number of goldfields in the area (collectively known as Lake Victoria Goldfields) and they are located in the Archean Nyanzian greenstone belt east and south of Lake Victoria in northwest Tanzania (Department of Geology, 1994). Mining is done at both small scale (artisanal) and large scale. The large scale gold mining companies include North Mara Gold Mine; Geita Gold Mine, Kahama Gold mine, and Buzwagi Gold mine just to mention a few. However, there are numerous artisanal gold mining activities spatially spread throughout the Lake Victoria 


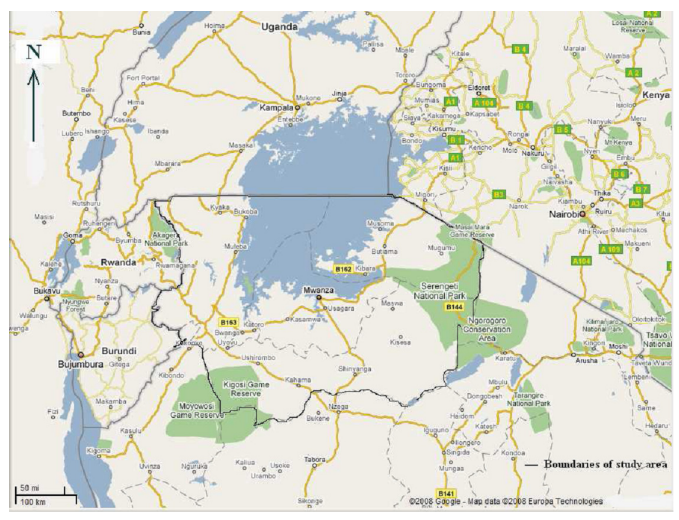

Figure 1. Location map of Tanzania showing the study area.

region. Both open cast and underground mining can expose the gold ores containing arsenic mineral to oxidation that lead to contamination of the groundwater sources. Probably management of tailing dumps contribute more to the arsenic pollution of the surface water sources. Such pollution exposes more than 12 million people in the Lake Victoria areas to a range of health risks.

Tanzania has adopted the WHO tolerant limit of $10 \mu \mathrm{gL}^{-1}$ (TZS 789: 2003). However, arsenic in Tanzania has not been an important or common variable for measurement in routine water quality analysis. Thus, its distribution in Tanzania is not yet clearly known. A rapid assessment was conducted in 2008 with the objective of determining the levels of arsenic contamination in drinking water sources in mining areas of the Lake Victoria Basin in Tanzania and information collected is part of this presentation.

\section{METHODS}

\subsection{Study area}

The study, which was conducted in 2008 in the Lake Victoria Basin in Tanzania, which covered some parts of the regions of Shinyanga, Mwanza, Geitia, Simiyu, and Mara. The study involved conducting field measurements of arsenic in selected water sources in the districts of Bariadi and Meatu (Simiyu Region); Bukombe, Maswa and Kahama (Shinyanga Region); Musoma and Serengeti (Mara Region); Geita (Geita Region) and Mwanza Urban, Sengerema, and Kwimba (Mwanza Region), as shown in Figure 1.

The total population in the Lake Victoria zone exceeds 12 million people, which is approximately $25 \%$ of the entire population of Tanzania (URT, 2012).

\subsection{Analytical methods}

The study involved carrying out in-situ measurement of arsenic levels in selected water sources in the

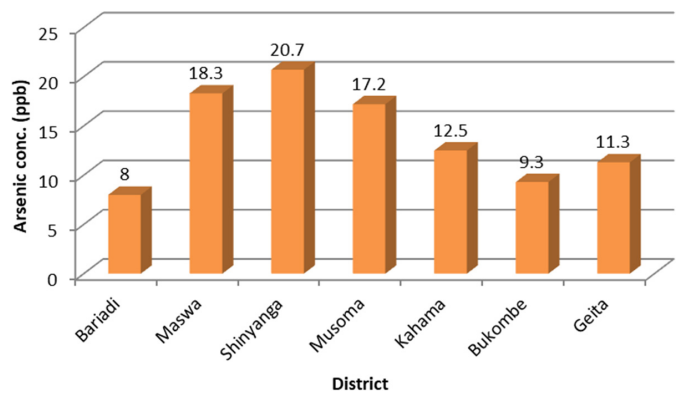

Figure 2. Measured average concentration levels of arsenic in selected water sources in the districts of the Lake Victoria mining areas, Tanzania.

districts. Only important water sources used for community water supply were selected. A total of 96 drinking water sources were selected and analysed for arsenic. The field studies involved onsite measurements of concentrations of arsenic and other associated parameters like iron and phosphorus. Field analysis of arsenic was done using Arsenic Test Kit (Hach Company, Loveland, CO), which has a detection limit of $5 \mu \mathrm{g} \mathrm{L}^{-1}$. The equipment uses visual comparison test and is ideal for use almost anywhere that trace amounts of total inorganic arsenic must be quantified. This kit uses safe, easy-to-handle reagents packaged in unit doses, with a test strip to determine the final result.

In this method, hydrogen sulfide is first oxidized to sulfate to prevent interference, and the oxidizing environment is then neutralized. Sulfonic acid and powdered zinc react to create strong reducing conditions in which inorganic arsenic is reduced to arsine gas $\left(\mathrm{AsH}_{3}\right)$. The arsine gas then reacts with mercuric bromide in the test strip to form mixed arsenic/mercury halogenides that discolor the test strip. The color ranges from yellow through tan to brown, depending on the concentration.

\section{RESULTS AND DISCUSSION}

\subsection{Arsenic contamination levels}

As earlier reported by Kassenga and Mato (2008), arsenic was detected in $58 \%$ of the water sources measured. This means that they had arsenic concentration exceeding $5 \mu \mathrm{g} \mathrm{L}^{-1}$, which was the detection limit of the equipment used. The actual data indicated a range of 5 to $70 \mu \mathrm{g} \mathrm{L}^{-1}$ with Maswa district showing the highest and Bariadi the lowest concentrations (see Figure 2). Moreover, more than 40\% of the analysed water sources had arsenic concentrations exceeding the Tanzania Drinking Water Quality Standards threshold value, which is $10 \mu \mathrm{g} \mathrm{L}^{-1}$.

Despite of showing high values of arsenic, Maswa district had no large scale mining activity, though artisanal mining has been going on in the areas for a long time. The districts of Kahama and Geita, which had large gold mines (Kaham and Geita gold mines), 
indicated a fairly low arsenic values of $5-30 \mu \mathrm{g} \mathrm{L}^{-1}$. The lowest arsenic contamination levels $\left(5-10 \mu \mathrm{g} \mathrm{L}^{-1}\right)$ were obtained in Bukombe and Bariadi districts, which did not have large scale mining activities. Nevertheless, arsenic contamination in the study area was observed to be less serious compared to the situation in other parts of the world reported elsewhere like Ghana, Bangladesh and USA (Welch et al., 2000; Smith et al., 2000; Smedley, 1996; Mukherjee et al., 2006).

Kassenga \& Mato (2008) argued that the fact that the observed arsenic concentrations in the study area in Tanzania are inconsequential compared to those reported in other gold mining areas should not be the reason for complacency. Efforts should be done to protect the rapidly increasing population in the Lake Victoria areas especially that arsenic is carcinogenic even at very low concentrations and the effect is cumulative (even at the WHO guideline of $10 \mu \mathrm{g} \mathrm{L}^{-1}$, the health risk is still $0.2 \%$ ).

Probably the most serious threat of arsenic contamination in water sources is increased mining activities in the Lake Victoria basin due to improved mining technologies and involvement of many more people in the sector. The current government drive towards industrialization will expand more the small and large scale mining activities that can be preceded by intensive mineral exploration activities. Unfortunately there exist inadequate environmental management practices of the tailing dumps and exploration holes. The problem is pronounced for small and medium scale mining companies which do not have sufficient resources to install appropriate mitigation measures to manage tailing dumps. Since there are no comprehensive studies, which have been undertaken to reveal the status of arsenic contamination of water sources in relation to on-going mining activities, it is difficult to tell the extent of the problem. However, referring to experiences in other countries, there is a serious potential public health risks due to arsenic contamination. The problem can be magnified by the fact that in the Lake Basin more than $67 \%$ of the households live more than a kilometre from a safe drinking water source (URT, 2002); and, that the Lake Victoria is generally dry with high evaporation rates (Sutcliffe \& Petersen, 2007) thus there is a possibility of concentrating the contaminant in water sources.

The conclusion by Kassenga \& Mato (2008) is that if left unattended the arsenic contamination problem in the Lake Victoria mining areas in Tanzania could sooner than later reach a crisis level. Since comprehensive studies to map arsenic contamination levels could prove to be costly and time demanding, a search for safe water sources can be a sustainable solution. Similar approaches have been adopted for other water sources contaminants by identifying sources with low or safe arsenic levels.

\section{CONCLUSION}

Arsenic contamination in Lake Victoria mining areas in Tanzania is a real public health threat. The problem is exacerbated by increased rates of mining activities in the areas and ever increasing population exposed to arsenic contamination. Searching for alternative safe water sources could save more lives especially in the poor rural areas.

\section{REFERENCES}

Bhattacharya, P., Sracek, O., Eldvall, B., Asklund, R., Barmen, G., Jacks, G., Koku, J., Gustafsson, J.E., Singh, N. \& Brokking, B.B. 2012. Hydrogeochemical Hydrogeochemical study on the contamination of water resources in a part of Tarkwa mining area, Western Ghana. J. Afr. Ear. Sci. 66-67: 72-84.

Department of Geology. 1994. Study on mercury and other heavy metal pollution in gold mining areas around Lake Victoria. (Unpublished report). University of Dar es Salaam, Dar es Salaam.

Halsey, P.M. 2000. Arsenic Contamination Study of Drinking Water in Nepal. PhD Thesis. Massachusetts Institute of Technology, Boston. p. 73.

Kassenga, G.R. \& Mato, R.R.A.M. 2008. Arsenic contamination levels in drinking water sources in mining areas in Lake Victoria Basin, Tanzania, and its removal using stabilized ferralsols. Int. J. Biol. Chem. Sci. 2(4): 389-400.

Mukherjee, A., Sengupta, M.K., Hossain, M.A., Ahamed, S., Das, B., Nayak, B, Lodh, D., Rahman, M.M. \& Chakraborti, D. 2006. Arsenic contamination in groundwater: a global perspective with emphasis on the Asian Scenario. J. Heal. Popul. Nutr. 24(2): 142-163.

Smedley, P.L. 1996. Arsenic in rural groundwater in Ghana. J. Afr. Earth. Sci. 22: 459-470.

Smith, A.H., Lingas, E.O. \& Rahman, M. 2000. Contamination of drinking water by arsenic in Bangladesh: a public health emergency. Bulletin of the World Health Organization 78(9): 1093-1103.

Sutcliffe, J.V. \& Petersen, G. 2007. Lake Victoria: derivation of a corrected natural water level series. Hydrol. Sci. J. 52(6): 1316-1321.

URT (United Republic of Tanzania). 2002. Population and Housing Census. National Bureau of Statistics: Dar es Salaam.

URT (United Republic of Tanzania). 2012. Population and Housing Census. National Bureau of Statistics: Dar es Salaam.

Welch, A.H., Westjohn, D.B., Helsel, D.R. \& Wanty, R.B. 2000. Arsenic in ground water of the United States: Occurrence and geochemistry. Ground Water 38: 589-604.

World Health Organisation (WHO). 2001. Arsenic and Arsenic Compounds. Second edition. Environmental Health Criteria 224, World Health Organization: Geneva. 


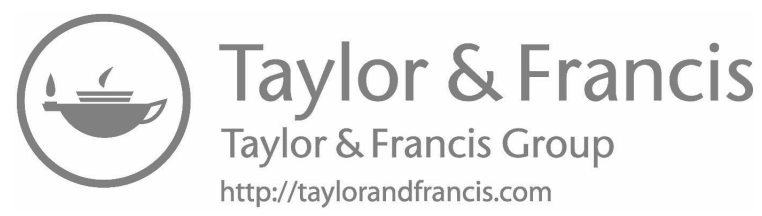


1.6 Arsenic mobility and fate in contaminated soils and sediments 


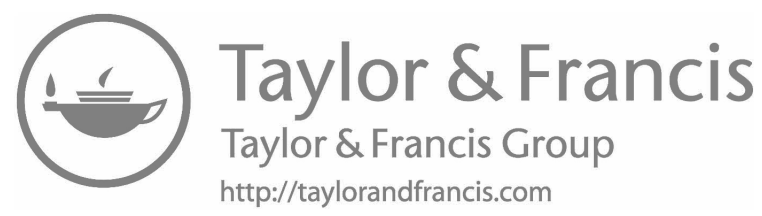

